\title{
Emergency Laparoscopic Cholecystectomy with Low Pressure Pneumo-Peritoneum in Cardiopulmonary Risk Patients: Fundus-Calot Cholecystectomy VS Calot first Cholecystectomy. Randomized Controlled Trial.
}

Tamer A.A.M Habeeb ( $\nabla$ tameralnaimy@hotmail.com )

zagazig university https://orcid.org/0000-0002-7049-4267

Gamal Osman

faculty of medicine zagazig university

Amr Ibrahim

zagazig university

Mohamed Riad

zagazig university

Abd-Elrahman M. Metwalli

zagazig university

Osama M.H. Khalil

zagazig university

Mohamed Ibrahim Mansour

zagazig university

Ahmed Shafik mohamed

zagazig university

Said mohamed negm

zagazig university

Tamer Wasefy

zagazig university

Muhammad Ali Baghdadi

zagazig university

Bassem Sieda

Zagazig University

Ashraf abdelmonem elsayed

Zagazig University

Mohamed Farouk Amin

Zagazig University 


\section{Wael M Abdalla}

zagazig university

Mostafa. M. Elaidy

Zagazig University

Walid A. Mawla

zagazig university

Khaled sharaf

Zagazig University

Mohamed I. Abdelhamid

Zagazig University

\section{Research article}

Keywords: Acute cholecystitis, Laparoscopy, Urgent cholecystectomy, fundus first

Posted Date: December 23rd, 2020

DOl: https://doi.org/10.21203/rs.3.rs-132819/v1

License: (c) (i) This work is licensed under a Creative Commons Attribution 4.0 International License. Read Full License 


\section{Abstract}

\section{Background:}

The numbers of elderly persons have greatly increased worldwide due to improvement of medical health. Elderly complains of cardiopulmonary diseases and the incidence of emergent gall bladder diseases increase with age. Laparoscopic cholecystectomy is the usual approach in dealing with cholithiasis that greatly replace open approach even in acute emergency gall bladder diseases.

Aim: compare between initial Fundus first cholecystectomy followed by Calot dissection VS Calot first cholecystectomy in Emergency laparoscopic cholecystectomy with low pressure pneumo-peritoneum in cardiopulmonary risk patients as regard intraoperative data and postoperative complications.

\section{Patients and methods:}

This prospective randomized controlled study was carried out in the Department of Emergency General Surgery on 470 cases with acute cholecystitis, biliary colic, mucocele and pyocele of gall bladder. The patients were divided into two groups, Group A: fundus-Calot group (235cases) and Group B (235cases): classical Calot first approach.

\section{$\underline{\text { Results }}$}

In most cases of group $A$, the operating time was up to 90 minutes, while in group B, most cases were more than 90 minutes. Intraoperative bleeding, visceral injury and biliary injury were higher in group $B$ than in group $A$ and therefore the conversion was higher in group $B$ than in group $A(14 \%$ vs. $4 \%$ ). Postoperative sequelae were reported to be greater than in group $B$ in regard to bleeding, biliary leakage and wound infections. Remote complications were more pronounced for biliary restrictions in Group B (14\%) than in Group A (2\%)

\section{Conclusion:}

Laparoscopic low-pressure pneumoperitoneum cholecystectomy with initial Fundus first method is an excellent and safe approach in treating acute gallbladder diseases in cardiopulmonary risk patients.

\section{Hypothesis}

laparoscopic cholecystectomy is safe in patients with cardiopulmonary disease using low pressure pneumoperitoneum and initial fundus first approach.

Our local Faculty of Medical Ethical Committee gave all ethical approvals

The described work has been carried out for human experiments in accordance with the World Medical Association's Code of Ethics (Helsinki Declaration). 
The work has been reported in line with consolidated standards of reporting trials (CONSORT) guidelines

\section{Introduction}

The advancement of laparoscopic cholecystectomy had greatly evolved making laparoscopic cholecystectomy is the commonest operation performed within the field of gastrointestinal tract surgery and almost replaced open cholecystectomy.[1][2]. Many advantages the patients gained as small operative wounds with minimal postoperative pain and infection and hence rapid discharge from hospital. Other advantages are better cosmetic results, earlier resumption of oral feeding and rapid restoration of daily activity and work.[3]

Many disadvantages emerged as higher incidence of bile duct injuries that may reach $0.3-0.8 \%$ that may increase in acute emergent cases. This may cause mortality in the patients. [4]Strasberg gave us the best solution up till now and the way to avoid injury to biliary tract. [5].Other complications the patients may face after laparoscopic cholecystectomy are organ injury; vascular injury and obstructive jaundice from missed stone in common bile duct during the operation. [6]

About $30 \%$ of patients undergo laparoscopic cholecystectomy are elderly patients with cardiopulmonary risks [7]. Pneumo-peritoneum with $\mathrm{CO} 2$ causes splintage of the diaphragm, hypercarbia with arrhythmias, compression of main abdominal vasculature (Inferior Vena Cava and abdominal aorta) and stretch of the peritoneal cavity with consequent parasympathetic irritation causing bradycardia.[8-12].

Head up position decreases venous return and hence cardiac output and increases the level of adrenaline in the blood, which leads to blood vasoconstriction, which increases peripheral resistance and decreases cardiac output, and increases myocardial load.[13-15]

The purpose of this study was to compare the outcome of urgent laparoscopic cholecystectomy in cardiopulmonary risk patients by either the fundus Calot approach or the Calot Classic approach as regard morbidity and mortality.

\section{The Aim Of The Work}

Compare the outcome of urgent laparoscopic cholecystectomy under low pressure Pneumo-peritoneum using either fundus first approach and Calot classic approach in cardiopulmonary risk patients as regard morbidity and mortality.

\section{Patients And Methods}

Study design: Prospective Randomized controlled clinical study.

Study place: our study was conducted in the colorectal surgical unit of our University Hospitals.

Study period: from March 2015 to March 2018. 
Source of data: Patients admitted with clinical diagnosis of emergent gall bladder diseases.

Sample size: 470

Sampling method: simple random sample with a balance

Method of sample size calculation: based on operation time difference between conventional and funds first group from previous paper with $80 \%$ power of study and $95 \%$ confidence interval. Ref Cengiz, Y., Lund, M., Jänes, A. et al. Fundus first as the standard technique for laparoscopic cholecystectomy.

Method of randomization:

1-Patients were randomly allocated using a random sequence generator. Random allocations were sequentially numbered in sealed opaque envelopes, which were opened during surgery before Carrying out the method of dissection. Patients were blinded to the assigned group until after the study.

2- It is done by the registration office

Patient selection criteria:

A. Inclusion criteria:

1. Male and Nonpregnant female of any age.

2. Patients with controlled cardiopulmonary diseases.

3. Patients who diagnose acute cholecystitis not improving on medical treatment for 48 hours.

4. Patients with biliary colic, mucocele of gall bladder and pyocele of gall bladder.

5. American Society of Anesthesiologist's (ASA) score: grade I, II \& III.

Exclusion criteria:

1. Patients refuse surgery.

2. Liver disease.

3. Previous percutaneous cholecystostomy

4. Cases not tolerated $\mathrm{CO} 2$ insufflation from the start.

Preoperative work up:

1. Full clinical examination

2. Ultrasonography

3. Blood investigations, liver functions.

4. Chest x-ray

5. ECG \& cardiac Echocardiography. 
In two groups patients are divided:

Group A ( $n=235)$ : patients were subjected to a laparoscopic cholecystectomy with low pressure pneumoperitoneum and initial fundus first cholecystectomy accompanied by Calot triangle dissections Group B ( $\mathrm{n}=235)$ : from the beginning, patients had laparoscopic cholecystectomy with low pressure pneumoperitoneum and first cholecystectomy with Calot.

\section{Methods:}

Through the periumbilical incision, A Hasson technique was used and a trocar is introduced into the abdomen under vision. Pneumoperitoneum was created 8-10 $\mathrm{mm} \mathrm{Hg}$. The camera was introduced and the abdominal cavity inspected. At epigastrium $5 \mathrm{~cm}$ below the xiphoid process a $10 \mathrm{~mm}$ trocar was placed. Only below the right margin was a third $5 \mathrm{~mm}$ trocar placed. The 4 th trocar is inserted on anterior axillary line at umbilical level.

Calot triangle first dissection: initial laparoscopic view showed distended gall bladder with mucocele and stone in gall bladder neck (pic 1). Difficult handling of Hartman due to stone impacted in neck of gall bladder (Pic 2). Dissection started at gall bladder neck which was difficult (pic 3). Adhesions to omentum, colon, duodenum or stomach are pulled away by blunt and diathermy dissection. Dissection continued very close to gall bladder wall. Identification of Calot triangle helped us to recognize the anatomy. Dissected and cut off and divided, are cystic duct and cystic artery. Hazards dissection in calot first approach may result in bleeding (pic 4). Rough retraction of the fundus may result in liver tear(pic 5). Then the gall bladder is difficulty freed from liver (pic 6). A hemostasis was inspected on the gallbladder bed and coagulation was achieved. The gallbladder was removed from the abdomen through the epigastric port. a drain is put in gall bladder bed.

Fundus first approach initial approach: we start dissection of the peritoneum at the side of gall bladder and perform dissection in inverted $U$ shaped incision in the peritoneum covering the side and fundus of gallbladder (pic 7)then the gall bladder is dissected free from gall bladder bed(pic 8). Then the fundus of the gallbladder is retracted towards easily to the right shoulder and start the exposure and dissection of the Calot triangle .in this way, dissection of Calot triangle became very easy. Sometimes aspiration of the gall bladder contents helped us to grasp the fundus.

Follow up [24 months]:

1-All patients were followed for 1 month, 3 month, 6 month and 12 months after hospital discharge. After discharge, patients were communicated by phone and follow up visit at outpatient clinic.

2- Methods of follow-up: clinical examination, full laboratory examination and imaging in patients developed symptoms of biliary stricture as magnetic resonance cholangiopancreatography. 
3-no patients lost during follow up period

Efforts to decrease bias in the study:

1. For pretrial bias: Good Define objectives. Risk and outcome .Select patients on probability sample with adequate sample size. Define confound factors and avoid it

2. To avoid during trial bias: Standardize reaction and management of patients blindly-Objective data use rather than subjective-Good handling of data- plan designed for drop out

3. To avoid after trial bias: Suitable statistical analysis used-Good and carefully interpretation-Control of confound

The Outcome measures:

1. Mortality (at maximum follow-up mortality of 90 days).

2. Complications post-operatives: early (bile leaks) or late (strict securing), Hernia port site

3. Conversion

4. Total stay in hospital (days).

5. Intraoperative findings

\section{Statistical Analysis}

Data entered and analyzed using (SPSS version 20.0) software for analysis. According to the type of data qualitative represent as number and percentage, quantitative continues group represent by mean $\pm S D$, the following tests were used to test differences for significance;. Difference and association of qualitative variable by Chi square test (X2) or Fisher's exact. Differences between quantitative independent groups by $t$ test. $P$ value was set at $<0.05$ for significant results $\&<0.001$ for high significant result.

\section{Results}

The study involved 470 patients. They were subdivided into 2 groups:

Group A: $(n=235)$ : Low-pressure pneumoperitoneum laparoscopic cholecystectomy and initial fundus of the first cholecystectomy.

Group B: $(n=235)$ : Patients underwent low pressure pneumoperitoneum laparoscopic cholecystectomy and first Calot dissection from the beginning.

Table (1) showed that age was distributed as $56.8 \pm 16.87$ and $53.6 \pm 17.95$ respectively between Group A \& Group B with no significant difference between groups regard sex distribution female were majority in 
both group with no significant difference between groups, $37 \%$ had DM in the 1 st group and $42 \%$ in the 2nd group had DM about one quarter had HTN at 1st group and about one third at 2nd group with no significant difference between groups regard DM or HTN, about third of $1^{\text {st }}$ group had obesity and about half of $2^{\text {nd }}$ group with no significant difference between groups also there was no significant difference regard Respiratory diseases, or previous upper abdominal surgery, Coronary disease was significantly higher at $1^{\text {st }}$ group and Valvular diseases was significantly higher at $2^{\text {nd }}$ group , there was significant difference regard diagnosis distribution as Biliary colic was the major diagnosis at 1 st groups and Pyocele \& Mucocele were the major diagnosis at $2^{\text {nd }}$ group

Operation time was significantly shorter at 1 st group , regard bleeding Cystic artery bleeding and liver bleeding was significantly associated with 2 nd group also 2 nd group was significantly associated with blood transfusion, regard latrogenic injury 2 nd group was significantly associated with liver injury and also 2 nd group was sig associated with Conversion to open.(Table 2).

ICU admission rate and mortality rate were significantly higher at 2 nd group. (Table 3 ).

. (Table 4) showed that postoperative bleeding was significantly associated with 2nd group

Biliary stricture was significantly associated with 2 nd group.(Table 5).

\section{Discussion}

A study indicated that $25-38 \%$ of the patients who complained of acute cholecystitis are elderly male diabetic patients underwent laparoscopic cholecystectomy [7]. in the present study, about 134 cases $(30 \%)$ of cases were elderly diabetic above 60 years mostly female and mostly complained of ASA II. About $67 \%$ of cases (315 cases) were above 40 years.

A study stated that previous upper abdominal surgery may increase the risk of viscous injury during trocar induction due to adhesion at the site of previous scar [8].In the present study; about $13 \%$ of cases in Group A underwent previous abdominal surgery and $6 \%$ in Group B. No viscus injury as all cases underwent Hasson technique for intra-abdominal access under direct vision.

Bradycardia may develop with induction of pneumoperitoneum due to distension of the peritoneum with parasympathetic irritation. If occurred, immediately deflate the abdomen [16]. In the present study, we started with $8 \mathrm{mmhg}$ intraperitoneal pressure and gradually increased to $10 \mathrm{mmhg}$ not more. Only 5 cases showed hypoxia and bradycardia.

Neri et al stated that the duration of laparoscopic cholecystectomy was shorter in fundus first approach than classical Calot first dissection (70 min and 90 min respectively) and difficult cases of Calot first dissection were converted into open approach without any attempts for fundus first approach. [17]. This is similar to our results that concluded that fundus first initial approach has shorter operative time that classic initial Calot dissection and most cases of fundus first approach took up to 90 minutes in Group A 
while in Group B, most cases took more than 90 minutes (55\%). This is attributed to the low pressure of intraperitoneum making the retracted fundus hits the anterior abdominal wall making exposure of Calot triangle very difficult but it is not in cases of initial fundus first approach.

Bleeding during operation may be either minor bleeding from cystic artery stump slippage and omental vessels bleeding or major bleeding from torn liver and big vascular injuries. Portal vein or hepatic artery bleeding may account for $0.03-10 \%$ of cases and is responsible for the second cause of death after complications related to anesthesia. [18].In this study, intraoperative bleeding occurred in Group A in $2 \%$ of cases from cystic artery bleeding (1\%) and omental blood vessel bleeding in (1\%).both cases were controlled laparoscopically. in Group B, most bleeding occurred from liver tear during extensive fundus traction in the hope to expose Calot triangle ( $7 \%$ ) that was controlled laparoscopically by electrocoagulation, cystic artery stump bleeding (7\%) and omental vessels bleeding (3\%) that controlled laparoscopically by ligation. Seven cases of bleeding cystic artery were controlled laparoscopically and eleven cases of cystic artery slippage bleeding cannot be controlled laparoscopy and required open exploration to control bleeding. No cases of major blood vessels injury occurred in both groups.

A study stated that fundus first cholecystectomy decrease the rate of complications [19] while other study stated the opposite. [20].In the present study, fundus first approach much decreased the complication rate. Dissection of the fundus first allow traction of the fundus easy in the condition of low intraperitoneal pressure that help expose of Calot triade then we start dissection in the Calot triade to get critical view of safety and adequate envision cystic duct, Common duct of bile, hence decrease the incidence of biliary injury. Intraoperative bile duct injury occurred in $1 \%$ of cases in Group A and it was minor common bile duct injury that repaired laparoscopy while the incidence was $5 \%$ of cases with Calot first dissection. Seven cases were minor common bile duct injury that repaired laparoscopically, two cases were transected common bile duct that necessitated open exploration and hepatico-jejunostomy, two cases were injury to right hepatic duct that necessitated exploration and repaired over T-tube drainage. Intraoperative bile duct injury is detected by staining the operative field with bile. Intraoperative colonic and duodenal injuries occurred in group B only and they were discovered intraoperative. Four cases of colonic injuries occurred and 2 of them were minor perforation that were controlled laparoscopy while the other 2 cases required exploration and repair in one case and simple loop colostomy in the other case that was closed after 2 month. Duodenal injuries occurred in 6 cases, 4 cases were minute perforation that is repaired laparoscopically by repair over omental patch, while 2 cases required exploration and repair the big tear with suture over omental patch and gastrojejunostomy.

Many studies stated that conversion rate with fundus first approach may be as low as $1.2 \%$ [21]. while other studies reported higher conversion rate $50 \%, 20 \%, 18.5 \%, 23 \%$ and $50 \%$ respectively.[22-26]. In the present study, Lower incidence in fundus first group (4\%) while the higher incidence were in Calot first approach (14\%).

Postoperative bleeding occurred in 3\% of Group A and $11 \%$ of Group B cases. Postoperatively these patients developed hypotension, tachycardia and continuous fresh bleeding from the drain. Initially these 
patients underwent conservative treatment in the form of fresh blood transfusion and intravenous fluid. two cases in group A continued to bleed and required re-exploration and revealed cystic artery clip slippage that was controlled by ligation and the other cases was due to post site bleeding that was controlled by trans fixation suture.in Group B, eight cases continue to bleed. Five cases due to slippage of cystic artery clip that were controlled by careful identification of the stump and ligation by suture. two cases were due to port site bleeding that were controlled by trans fixation sutures(figure of 8 ).the last case was due to greater omental portal arteries that is big enough that required ligation.

In several literatures, up to $1.3-1.5 \%$ can occur in bile duct injuries with biliary leakage after laparoscopic cholestectomy. [27-28].Other literature described incidence up to 3\%. [29]. in the present study, postoperative biliary leakage is noted in $2 \%$ of Group $A$ and $6 \%$ in group B. the condition is diagnosed postoperative by abdominal pain, fever, sonar evidence of gall bladder bed collection that revealed bile by aspiration and bile drainage from intra-abdominal drain. Most cases were found in 2-3 days after surgery. Cases of drying less than $200 \mathrm{~mL}(n=10)$ of the bile have undergone conservative treatment in the form of nothing in the oral, cephalosporin and spasmolytic in the third generation, with sonary catheter drainage of the collections. Three cases draining more than $500 \mathrm{ml}$ of bile per day underwent urgent endoscopic retrograde cholangiopancreatography with plastic stenting. Most cases were slipped cystic duct stump clips and others were minor common bile duct injury. These cases improved immediately with no bile drainage from the drain. Three cases showed complete cut of right hepatic duct in two cases and transection common bile duct in one case with dye extravasation on ERCP and treated with re-exploration and hepaticojejunostomy.

A study stated that surgical site infection is common in emergent cholecystectomy. [30]. In this study, $2 \%$ of cases in Group A and 5\% in Group B .

Postoperative biliary strictures developed in $2 \%$ of cases of group A and $14 \%$ in group B. mostly discovered after 10th months postoperatively. Patients present with abdominal pain, slight jaundice and elevated liver enzyme. All cases underwent ERCP with balloon dilatation and stenting.

In the present study, the incidence of mortality was $2 \%$ in group A and $9 \%$ in group B. 2 cases underwent laparoscopic approach died of bradycardia and cardiac arrest (one case), the other died of biliary injury sequelae. These cases died in 2nd day and 7th day postoperatively. 21 cases underwent open cholecystectomy showed mortality. bradycardia with heart arrest(2 cases),biliary fistula sequelae (4 cases),colonic injury(one case),duodenal injury(two cases),hypertensive stroke(2 cases) and atelectasis(10 cases).

\section{Conclusions}

Fundus first approach is safe and excellent approach to such patients as this enable rapid operation, adequate fundus retraction in low pressure pneumoperitoneum and hence excellent exposure of Calot triangle to complete safe cholecystectomy. Also, low $\mathrm{CO} 2$ pressure had favorable effect on heart and 
lung. We state that low pressure pneumoperitoneum with fundus first approach add safety to the patients during surgery especially in ASA grade III.

\section{Recommendation}

Laparoscopic cholecystectomy is not more contraindicated in high risk cardiopulmonary patients.

\section{Limitations}

The choice of patients operated at night may have been affected by a selection bias. This might have favored our analysis of the risk factor. Also, ASA more than three is not included in the study, because no cases encountered during the study period.

\section{Abbreviations}

D.M: diabetes mellitus

HTN: hypertension

ICU: intensive care unit

\section{Declarations}

Registration Criteria for registering on the quality control review protocol on clinicaltrials.gov protocol: NCT04368611 registered on 28 April 2020.

\section{a- Ethics approval, consent to participate}

Yes, our Faculty of Medical Ethical Committee Zagazig University gave all the ethical approval.

Before the study was included, all involved persons gave their informed consent.

B-Consent for publication: after the study was included, all involved persons gave their informed consent for publication.

\section{c-Authors' contributions:}

All authors shared important intellectual content in study design, analysis of data, writing and critical review of the manuscript. They participated in the final approval of the submitted version.

d-Availability of Data and materials: they are not applicable

e-Competing interests: The authors declare that they have no competing financial or non-financial competing interests. 
F-Acknowledgement: we would like to thank professor Abdel-rahman Sarhan and all members of laparoscopic unit in faculty of medicine Zagazig University for their great help and recommendations.

G-Funding: no

\section{References}

1. Karimian F, Aminian A, Mirsharifi R, et al. Surgical options in the management of cystic duct avulsion during laparoscopic cholecystectomy. Patient Saf Surg. 2008;2:17.

2. Duman K, Sezer KH, Yılmaz F, et al. The clinical outcome of traditional laparoscopic Cholecystectomy. Gaziantep Med J. 2013;19(1):35-9.

3. Nuzzo G, Giuliante F, Giovannini I, et al. Bile duct injuryduring laparoscopic cholecystectomy: results of an Italian national survey on cholecystectomies. Arch Surg. 2005;140:986-92.

4. Kreimer F, Cunha DJ, Ferreira CC, et al. Comparative analysis of preoperative ultrasonography reports with intraoperative surgical findings in cholelithiasis. Arq Bras Cir Dig. 2016 Mar;29(1):26-9.

5. Strasberg SM, Brunt LM. Rationale and Use of the Critical View of Safety in Laparoscopic Cholecystectomy. J Am Coll Surg. 2010;211(1):132-8.

6. Zehetner J, Shamiyeh A, Wayand W. Lost gallstones in laparoscopic cholecystectomy: all possible complications. The American Journal of Surgery. 2007;193:73-8.

7. Roslyn JJ, Binns GS, Hughes EF, et al. Open cholecystectomy: a contemporary analysis of 42,474 patients. Ann Surg. 1993;218:129-37.

8. Gurusamy KS, Rossi M, Davidson BR. Percutaneous cholecystostomy for high-risk surgical patients with acute calculous cholecystitis. " Cochrane Database of Systematic Reviews. 2013;8:CD007088.

9. Cullen DJ, Coyle JP, Teplick R, et al. Cardiovascular, pulmonary, a nd renal effects of massively increased intra-abdominal pressure in critically ill patients. Crit Care Med. 1989;17:118-21.

10. O’Malley C, Cunningham AJ. Physiologic changes during laparoscopy. Anesthesiol Clin North America. 2001;19:1-19.

11. O'Leary E, Hubbard K, Tormey W, et al. Laparoscopic cholecystectomy: haemodynamic and neuroendocrine responses after pneumoperitoneum and changes in position. $\mathrm{Br} \mathrm{J}$ Anaesth. 1996;76:640-4.

12. Gutt CN, Oniu T, Mehrabi A, et al. Circulatory and respiratory complications of carbon dioxide insufflation. Dig Surg. 2004;21:95-105. doi:10.1159/000077038.

13. Cunningham AJ. Anesthetic implications of laparoscopic surgery. Yale J Biol Med. 1998;71:551-78.

14. Gannedahl P, Odeberg S, Brodin LA, et al. Effects of posture and pneumoperitoneum during anaesthesia on the indices of left ventricular filling. Acta Anaesthesiol Scand. 1996;40:160-6.

15. Hirvonen EA, Nuutinen LS, Vuolteenaho 0 . Hormonal responses and cardiac filling pressures in headup or head-down position and pneumoperitoneum in patients undergoing operative laparoscopy. $\mathrm{Br} \mathrm{J}$ Anaesth. 1997;78:128-33. 
16. Yong J, Hibbert P, Runciman WB, et al. Bradycardia as an early warning sign for cardiac arrest during routine laparoscopic surgery. Int J Qual Health Care. 2015;27:473-8. doi:10.1093/intqhc/mzv077.

17. Neri $V$, Ambrosi A, Fersini A, et al. Antegrade dissection in laparoscopic cholecystectomy. JSLS. 2007;11:225-8.

18. Schäfer M, Lauper M, Krähenbühl L. A nation's experience of bleeding complications during laparoscopy. Am J Surg. 2000;180:73-7.

19. Hussain A. Difficult laparoscopic cholecystectomy: current evidence and strategies of management. Surg Laparosc Endosc Percutan Tech. 2011;21:211-7. [CrossRef].

20. Strasberg SM, Gouma DJ. 'Extreme' vasculobiliary injuries: association with fundus-down cholecystectomy in severely inflamed gallbladders. HPB (Oxford). 2012;14:1-8. [CrossRef].

21. Mahmud S, Masaud M, Canna K, et al. Fundus-first laparoscopic cholecystectomy. Surg Endosc. 2002;16:581-4. [CrossRef].

22. Navez B, Mutter D, Russier Y, et al. Safety of laparoscopic approach for acute cholecystitis: retrospective study of 609 cases. World J Surg. 2001;25:1352-6.

23. Prakash K, Jacob G, Lekha V, et al. Laparoscopic cholecystectomy in acute cholecystitis. Surg Endosc. 2002;16:180-3.

24. Bender JS, Duncan MD, Freeswick PD, et al. Increased laparoscopic experience does not lead to improved results with acute cholecystitis. Am J Surg. 2002;184:591-5.

25. Lo CM, Lai EC, Fan ST, et al. Laparoscopic cholecystectomy for acute cholecystitis in the elderly. World J Surg. 1996;20:983-7.

26. Magnuson TH, Ratner LE, Zenilman ME, et al. Laparoscopic cholecystectomy: applicability in the geriatric population. Am Surg. 1997;63:91-6.

27. Kum CK, Goh PM, Isaac JR, et al. Laparoscopic cholecystectomy for acute cholecystitis. Br J Surg. 1994;81:1651-4.

28. Adamson $\mathrm{S}$, Hansen $\mathrm{OH}$, Funch-Jensen $\mathrm{P}$, et al. Bile duct injury during laparoscopic cholecystectomy: a prospective nationwide series. J Am Coll Surg. 1997;184:571-8. [PubMed] [Google Scholar].

29. Unger W, Glick G, Landeros M. Cystic duct leak after laparoscopic cholecystectomy: a multiinstitutional study. Surg Endosc. 1996;10:1189-93. [PubMed] [Google Scholar.

30. Hussain A, Mahmood $H$, Singhal T, et al. Long-term study of port-site incisional hernia after laparoscopic procedures. JSLS. 2009;13:346-9.

\section{Tables}

\section{RESULTS}

The study involved 470 patients. They were subdivided into 2 groups:

Group A: $(n=235)$ : Low-pressure pneumoperitoneum laparoscopic cholecystectomy and initial fundus of the first cholecystectomy.. 
Group B: $(n=235)$ : Patients underwent low pressure pneumoperitoneum laparoscopic cholecystectomy and first Calot dissection from the beginning.

Table 1: demographic and preoperative data 


\begin{tabular}{|c|c|c|c|c|}
\hline & $\begin{array}{l}\text { Group A } \\
(\mathrm{n}=235)\end{array}$ & $\begin{array}{l}\text { Group B } \\
(\mathrm{n}=235)\end{array}$ & $x^{2} / t$ & $\mathrm{p}$ \\
\hline \multicolumn{5}{|l|}{ Age (years). } \\
\hline$<40$ years & $40(17 \%)$ & $54(23 \%)$ & \multirow{3}{*}{4.22} & \multirow{3}{*}{0.11} \\
\hline $40-59$ & $131(55.7 \%)$ & $110(47 \%)$ & & \\
\hline$>60$ & $64(27.3 \%)$ & $70(30 \%)$ & & \\
\hline Mean $\pm S D$ & $56.8 \pm 16.87$ & $53.6 \pm 17.95$ & $t=1.69$ & $P=0.081$ \\
\hline \multicolumn{5}{|l|}{$\underline{\text { Sex }}$} \\
\hline Female & $177(75.3 \%)$ & $190(80.8 \%)$ & \multirow[t]{2}{*}{2.11} & \multirow[t]{2}{*}{0.14} \\
\hline Male & $58(29 \%)$ & $45(19.2 \%)$ & & \\
\hline \multicolumn{5}{|l|}{ Systemic diseases } \\
\hline D.M & $87(37 \%)$ & $99(42 \%)$ & 0.31 & 0.57 \\
\hline HTN & $56(24 \%)$ & 77(33\%) & 1.42 & 0.23 \\
\hline Obesity & $87(37 \%)$ & $106(45 \%)$ & 0.78 & 0.37 \\
\hline \multicolumn{5}{|l|}{$\begin{array}{l}\text { American society of anesthesiologist } \\
\text { score }\end{array}$} \\
\hline \multicolumn{2}{|c|}{$54(229 \%)$} & $54(22.9 \%)$ & & \multirow{3}{*}{0.13} \\
\hline \multirow{2}{*}{ II } & $141(60 \%)$ & $129(55 \%)$ & \multirow[t]{2}{*}{4.07} & \\
\hline & $35(15 \%)$ & $52(22.1 \%)$ & & \\
\hline \multicolumn{5}{|l|}{ Respiratory diseases(Bronchial } \\
\hline Asthma-C.O.P.D) & $87(37 \%)$ & $59(25 \%)$ & 2.32 & 0.12 \\
\hline Coronary disease (angina-MI) & $134(57 \%)$ & $80(34 \%)$ & 5.81 & $0.015^{\star}$ \\
\hline Valvular diseases. & $14(6 \%)$ & $96(41 \%)$ & 26.06 & $0.00 * \star$ \\
\hline Previous upper abdominal surgery & $30(13 \%)$ & $14(6 \%)$ & 2.57 & 0.11 \\
\hline \multicolumn{5}{|l|}{ Diagnosis } \\
\hline Acute calcular cholecystitis & $23(10 \%)$ & $37(16 \%)$ & \multirow{5}{*}{27.19} & \multirow{5}{*}{$0.00 * \star$} \\
\hline Acute non calcular cholecystitis & $16(6.8 \%)$ & $7(2.9 \%)$ & & \\
\hline Biliary colic & $87(37 \%)$ & $45(19 \%)$ & & \\
\hline Mucocele & $61(26 \%)$ & $70(30 \%)$ & & \\
\hline pyocele & $47(20 \%)$ & $75(32 \%)$ & & \\
\hline
\end{tabular}


Age was distributed as $56.8 \pm 16.87$ and $53.6 \pm 17.95$ respectively between Group A \& Group B with no significant difference between groups regard sex distribution female were majority in both group with no significant difference between groups , $37 \%$ had DM in the 1 st group and $42 \%$ in the 2 nd group had DM about one quarter had HTN at 1st group and about one third at 2nd group with no significant difference between groups regard DM or HTN, about third of $1^{\text {st }}$ group had obesity and about half of $2^{\text {nd }}$ group with no significant difference between groups also there was no significant difference regard Respiratory diseases, or previous upper abdominal surgery, Coronary disease was significantly higher at $1^{\text {st }}$ group and Valvular diseases was significantly higher at $2^{\text {nd }}$ group , there was significant difference regard diagnosis distribution as Biliary colic was the major diagnosis at 1 st groups and Pyocele \& Mucocele were the major diagnosis at $2^{\text {nd }}$ group

\section{Table 2: intraoperative data}




\section{Group A}

Group B

$\mathrm{x}^{2} / \mathrm{t}$

$\mathrm{p}$

\section{Duration of operation(skin incision to \\ closure).}

$<60 \mathrm{~min}$

$60-90$

$>90 \mathrm{~min}$

Mean $\pm S D$

$35(14.8 \%) \quad 17(7.2 \%)$

$141(60 \%) \quad 87(37 \%) \quad 47.15 \quad 0.00$ **

$59(25.2 \%) \quad 131(55.8 \%)$

$\begin{array}{llll}75.85 \pm 27.5 & 98.63 \pm 27.6 & 21.36 & 0.00 * *\end{array}$

\section{Intraoperative bleeding}

Cystic artery bleeding

$2(0.8 \%) \quad 18(7.6 \%) \quad 4.55 \quad 0.03$ *

Liver bleeding

$0(0.0 \%) \quad 16(6.8 \%) \quad$ Fisher

exact $\mathbf{= 4 . 9 5}$

$0.021^{*}$

Omental vessel bleeding

$2(0.8 \%) \quad 6(2.5 \%)$

0.98

0.31

\section{latrogenic injury.}

Bile duct injury

$2(0.8 \%)$

$11(4.6 \%)$

2.67

0.101

Liver injury

$0 \%$

22(9.3\%)

Fisher

exact $=7.46$

$0.006^{*}$

Colonic injury

$0 \%$

$4(1.7 \%)$

$0 \%$

$6(2.5 \%)$

Fisher

Duodenal injury

exact $=0.22$

0.63

Fisher

exact $=0.92$

Conversion to open

$9(3.8 \%)$

$34(14 \%)$

5.84

$0.015^{\star}$

Causes of conversion

Obscure anatomy

$3(1.2 \%)$

8(3.4\%)

1.05

0.31

Difficult dissection in Callot triangle

$3(1.2 \%)$

$7(2.9 \%)$

0.77

0.4

Uncontrolled bleeding from cystic artery

$3(1.2 \%)$

$11(5 \%)$

2.32

0.12

Colonic injury

Duodenal injury

0

$2(0.8 \%)$

0

$2(0.8 \%)$

0

$4(1.7 \%)$

Fisher

exact $=0.05$

0.82

Bile duct injury

Fisher

exact $=0.05$

0.82

Fisher

exact $=0.28$ 
Operation time was significantly shorter at $1^{\text {st }}$ group , regard bleeding Cystic artery bleeding and liver bleeding was significantly associated with $2^{\text {nd }}$ group also $2^{\text {nd }}$ group was significantly associated with blood transfusion, regard latrogenic injury $2^{\text {nd }}$ group was significantly associated with liver injury and also $2^{\text {nd }}$ group was sig associated with Conversion to open

Table 3: postoperative data

\begin{tabular}{|lllll|}
\hline & Group A & Group B & $X^{2}$ & P \\
\hline ICU admission & $8(3.4 \%)$ & $33(14 \%)$ & 6.45 & $0.011^{*}$ \\
\hline mortality & $4(1.7 \%)$ & $21(8.9 \%)$ & 4.89 & $0.026^{*}$ \\
\hline
\end{tabular}

ICU admission rate and mortality rate were significantly higher at $2^{\text {nd }}$ group

Table 4: early postoperative complications

\begin{tabular}{|c|c|c|c|c|}
\hline & Fundus first & classic & $x^{2}$ & $\mathrm{P}$ \\
\hline Postoperative bleeding & $6(2.5 \%)$ & $26(11 \%)$ & 5.35 & $0.02^{\star}$ \\
\hline Bile leakage & $4(1.7 \%)$ & $12(5.1 \%)$ & 1.81 & 0.19 \\
\hline Wound infection & $4(1.7 \%)$ & $12(5.1 \%)$ & 1.81 & 0.19 \\
\hline Intra-abdominal collection & $8(3.4 \%)$ & $16(6.8 \%)$ & 1.13 & 0.28 \\
\hline \multicolumn{5}{|l|}{ Re-exploration } \\
\hline Cystic artery stump leakage & $3(1.2 \%)$ & $5(2.1 \%)$ & 0.24 & 0.62 \\
\hline Port site bleeding & $1(0.4 \%)$ & $2(0.8 \%)$ & 0.13 & 0.71 \\
\hline Omental bleeding & $0(0.0 \%)$ & $1(0.4 \%)$ & 0.91 & 0.34 \\
\hline Missed intestinal injury & $0(0.0 \%)$ & $5(2.1 \%)$ & 0.57 & 0.43 \\
\hline Biliary fistula & $3(1.2 \%)$ & $3(1.2 \%)$ & 0.0 & 1.0 \\
\hline
\end{tabular}

Postoperative bleeding was significantly associated with $2^{\text {nd }}$ group

Table 5: late postoperative complications 


\begin{tabular}{|lcccc|}
\hline & Group A & Group B & $X^{2}$ & $P$ \\
\hline Biliary stricture & $4(1.7 \%)$ & $33(14 \%)$ & 9.63 & $0.001^{\star *}$ \\
\hline port site hernia & $8(3.4 \%)$ & $16(6.8 \%)$ & 1.13 & 0.28 \\
\hline
\end{tabular}

Biliary stricture was significantly associated with $2^{\text {nd }}$ group

\section{Figures}

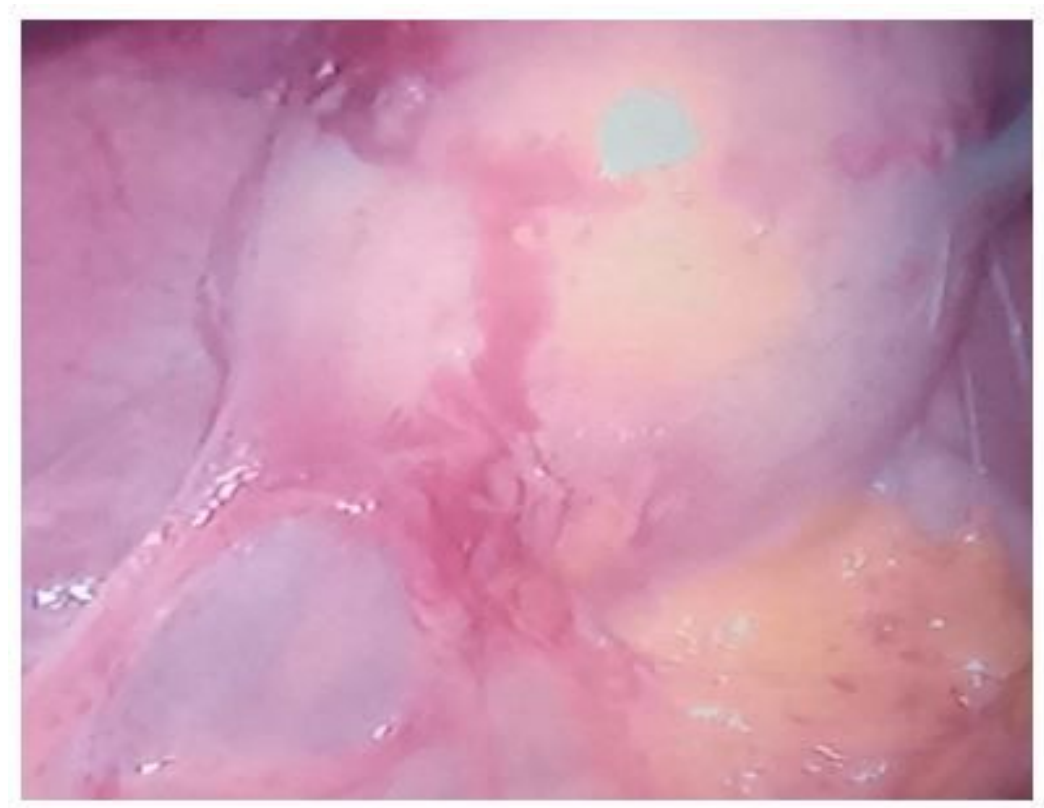

\section{Figure 1}

laparoscopic view showing distended gall bladder with mucocele and stone in gall bladder neck 


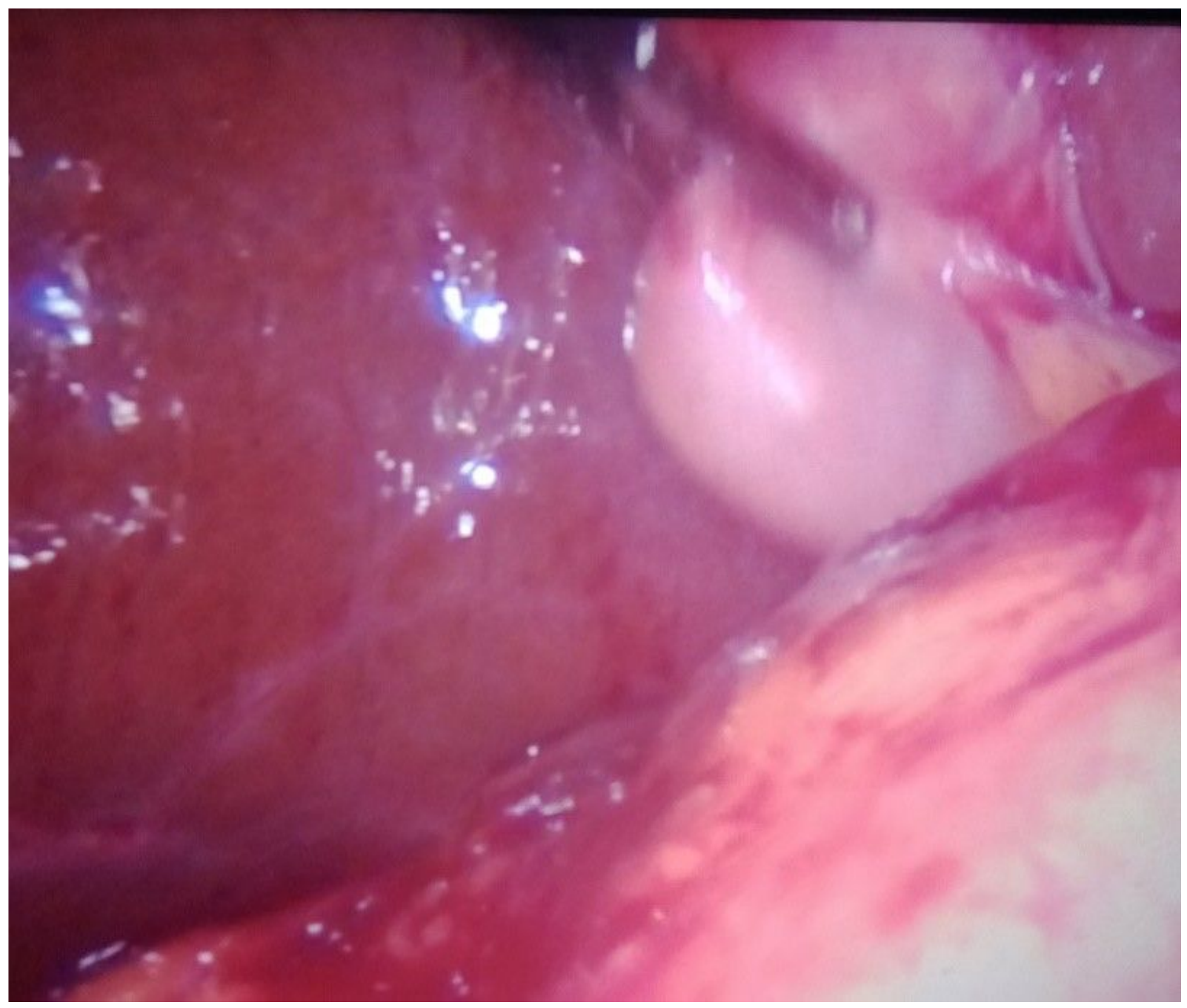

Figure 2

difficult handling of Hartman due to stone impacted in neck of gall bladder 


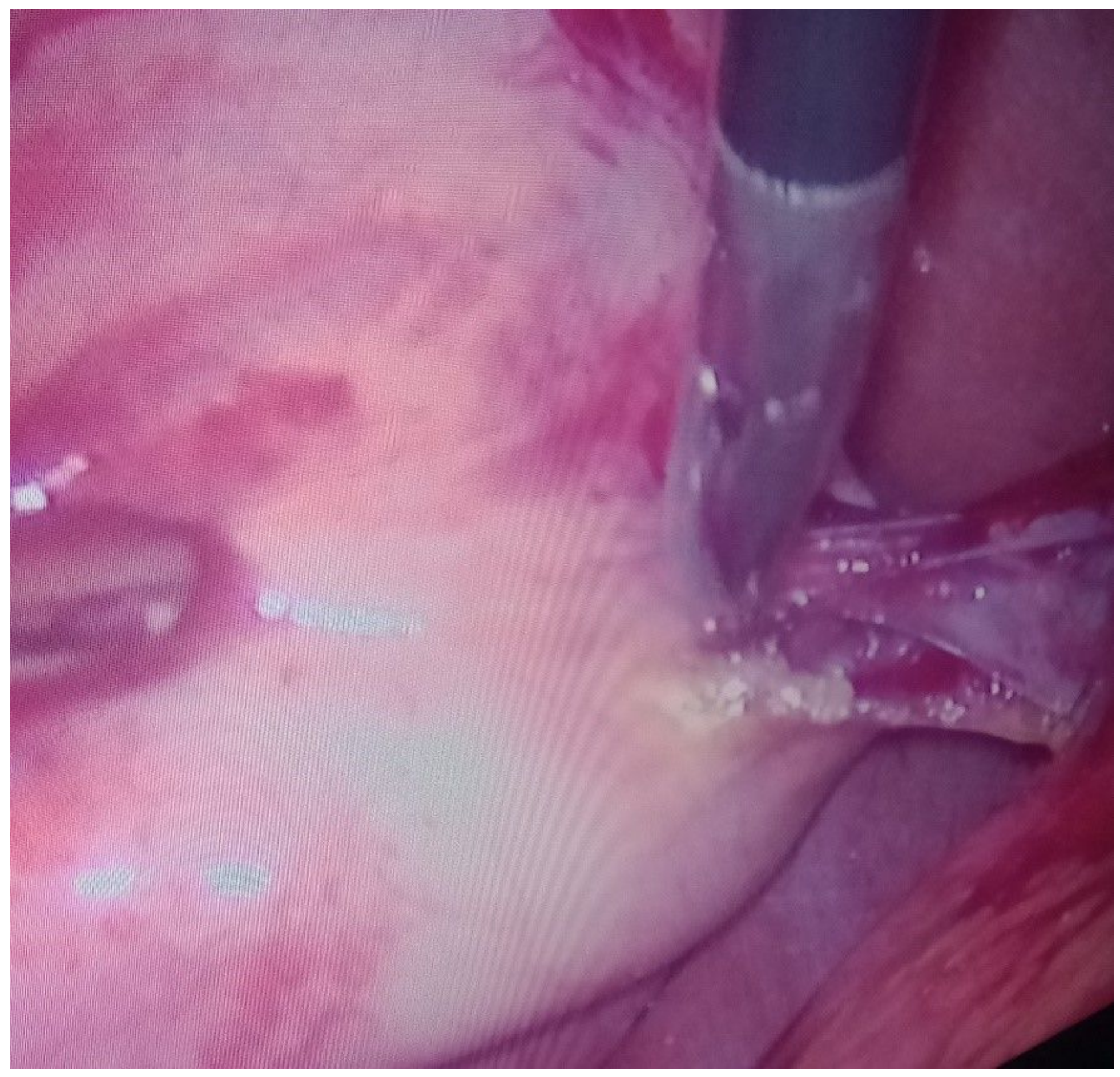

Figure 3

difficult dissection of calot triangle in patient with calot first dissection 


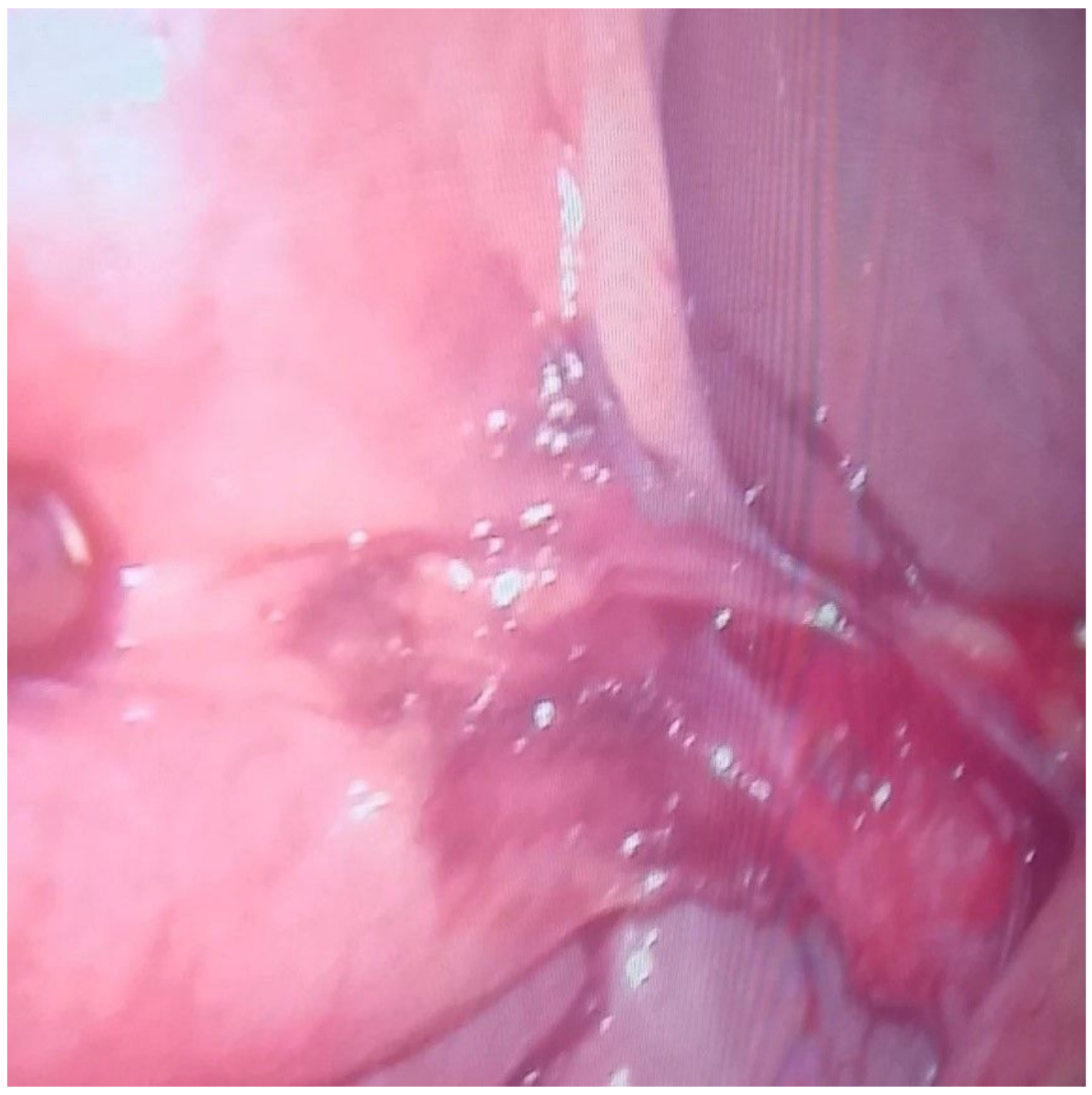

Figure 4

hazards dissection in calot first approach may result in bleeding 


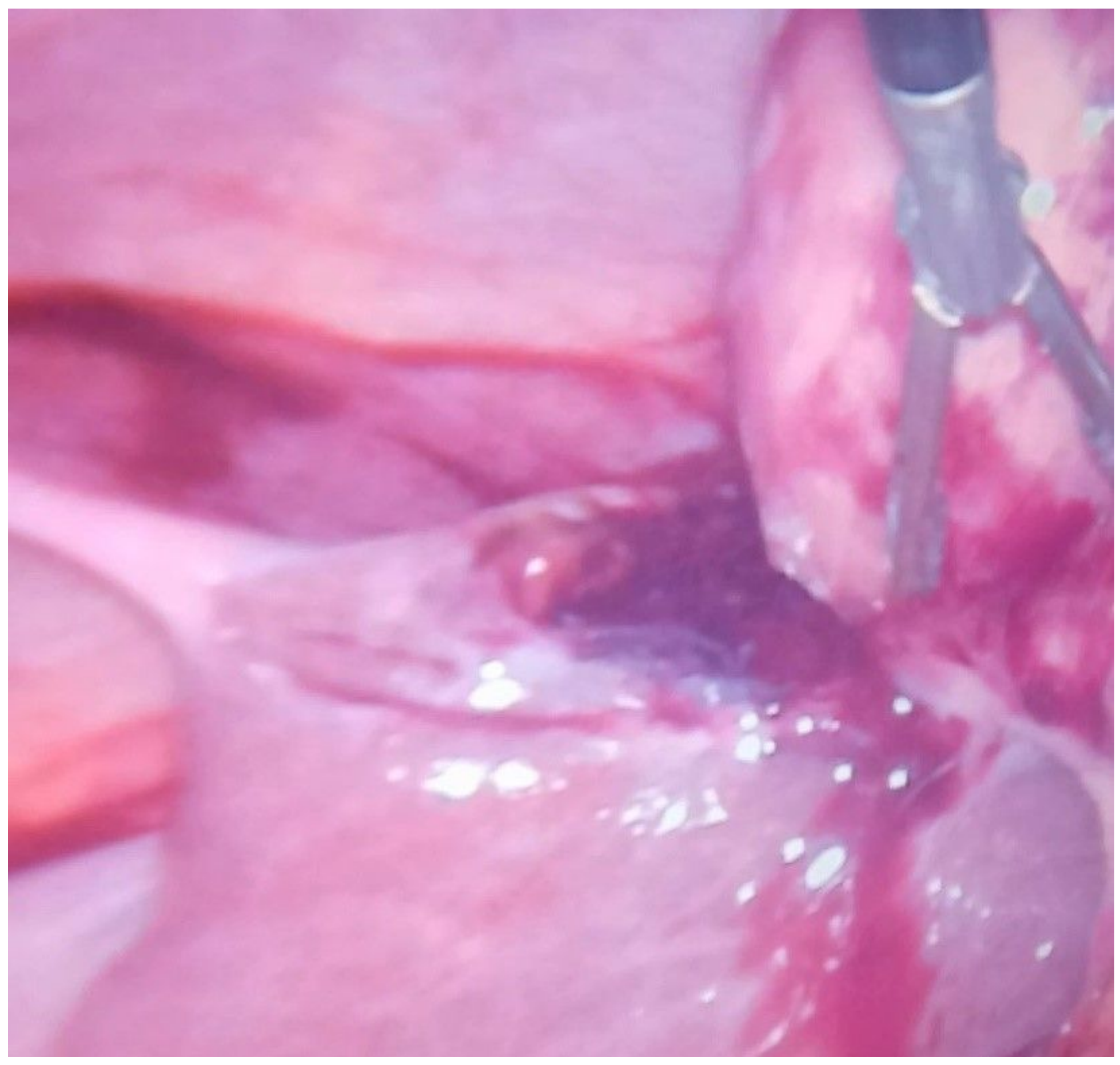

\section{Figure 5}

rough retraction of the fundus may result in liver tear 


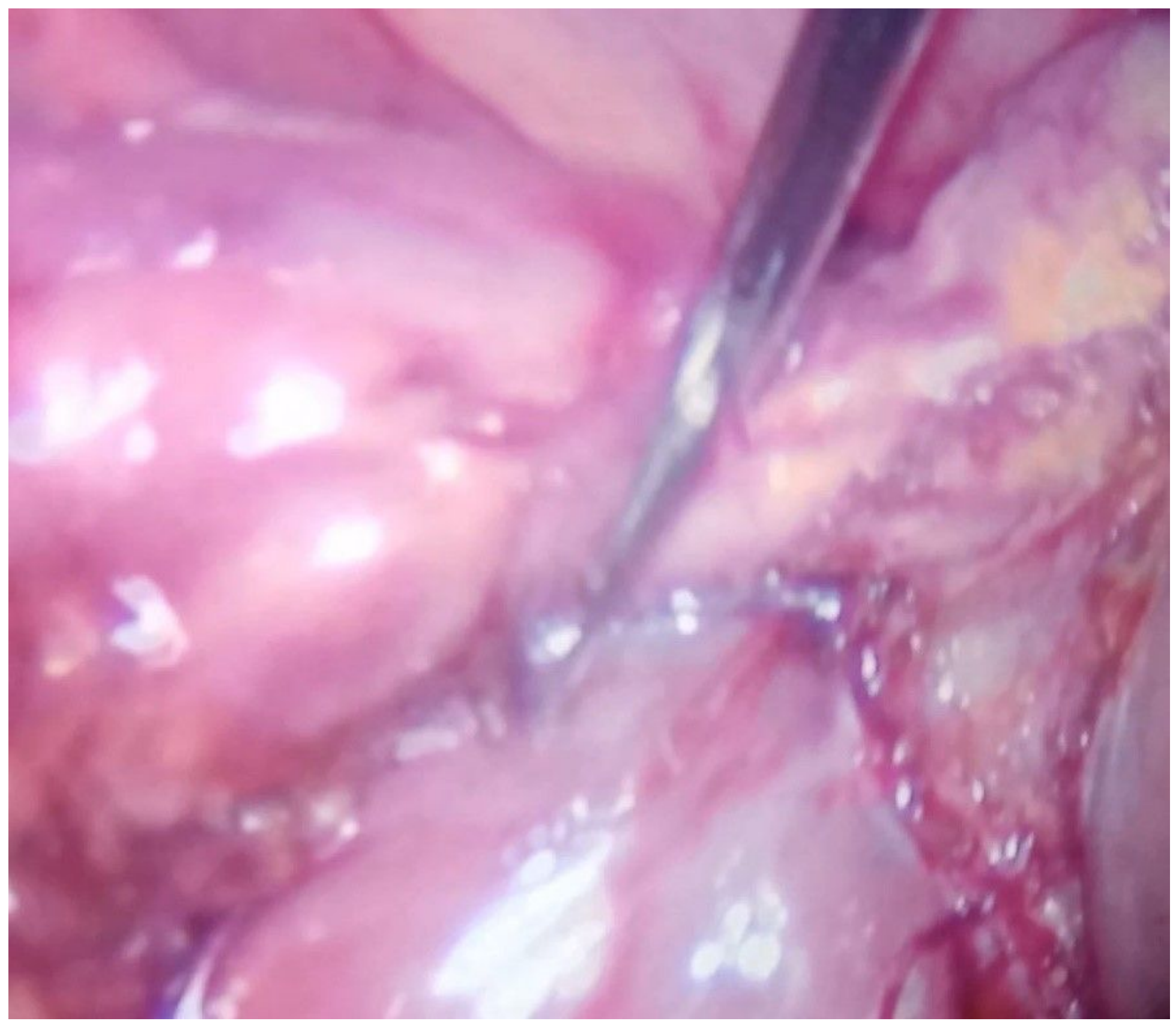

\section{Figure 6}

final dissection of the fundus of gall bladder in calot first approach is difficult due to low pressure pneumoperitoneum 


\section{Figure 7}

fundus -calot dissection started by opening the peritoneum at the side of gall bladder 


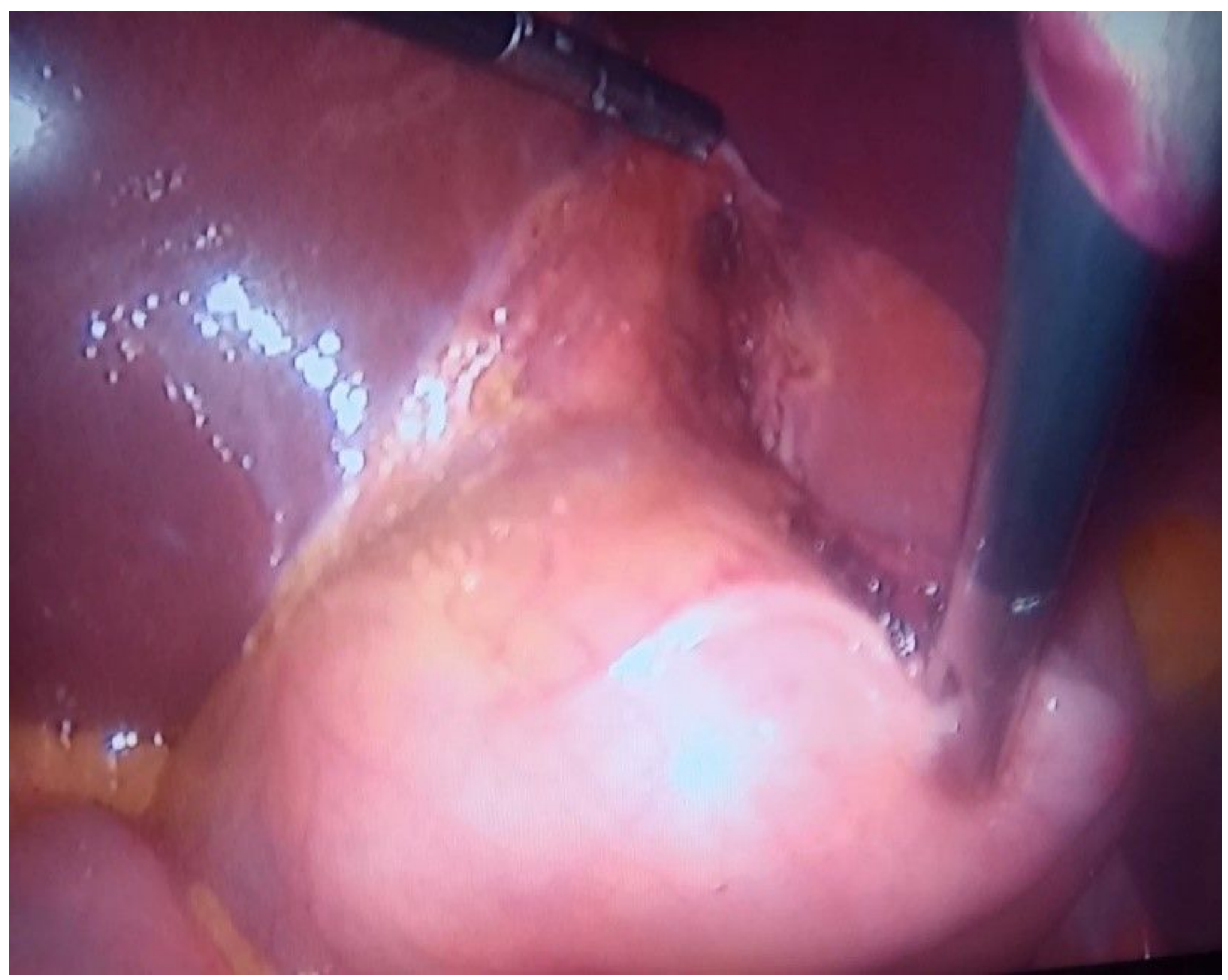

Figure 8

inverted u-shaped incision in the peritoneum around fundus of gall bladder that helps retraction of the bladder neck and also prevents difficult final step of gall bladder removal 